\title{
Managing Focal Nodular Hyperplasia of the Liver: Surgery or Minimally-invasive Approaches? A Review of the Preferable Treatment Options
}

\author{
EDOARDO VIRGILIO and MARCO CAVALLINI
}

\author{
Department of Medical and Surgical Sciences and Translational Medicine, St. Andrea Hospital, \\ Faculty of Medicine and Psychology, Sapienza University, Rome, Italy
}

\begin{abstract}
Background/Aim: Focal nodular hyperplasia $(F N H)$ is the second most common benign tumor of the liver. As of 2017, many clinical, radiological and surgical features have been largely documented. On the other hand, little is still known about the correlation of FNH with hepatocellular carcinoma, nor the preferable modality of treatment. Our aim was to elucidate the latter topic. Materials and Methods: We investigated the pertinent literature available as of 2017 through four popular search engines (PubMed, Science Direct, Scopus and Google Scholar). Four main approaches were selected: conservative treatment, surgery, radiofrequency ablation (RFA) and transarterial embolization (TAE). Results: We found most works to be on conservative and surgical approaches. On the contrary, only one article has been published for RFA to date. Seventeen articles dealt with TAE. Conclusion: TAE currently represents the most cogent and successful alternative to surgery.
\end{abstract}

Although rare, focal nodular hyperplasia $(\mathrm{FNH})$ is the second most common benign tumor of the liver after hemangioma and affects approximately $3 \%$ of the general population (1). Some of its clinicopathological features are well known: it arises from a vascular malformation, more frequently affects females (F/M: 8/1), may be exacerbated by oral contraceptive therapy, and magnetic resonance imaging with

Correspondence to: Dr. Edoardo Virgilio, Department of Medical and Surgical Sciences and Translational Medicine, Division of Emergency Surgery, Faculty of Medicine and Psychology, University "Sapienza", St. Andrea Hospital, via di Grottarossa 1035-39, Rome 00189, Italy. Tel: +39 0633775989, Fax: +39 0633775322, e-mail: aresedo1992@yahoo.it, edoardo.virgilio@uniroma1.it

Key Words: Focal nodular hyperplasia, $\mathrm{FNH}$, transarterial embolization, TAE, hepatocellular carcinoma, HCC, review. hepatobiliary-specific contrast, showing the characteristic central stellate scar, is by far the most appropriate radiological method for noninvasive diagnosis (1-5). Differential diagnosis includes benign (such as hepatic adenoma and inflammatory pseudotumor) as well as malignant lesions (6). On the other hand, as of 2017, what is still under evaluation regarding this disease is its malignant potential for hepatocellular carcinoma (HCC) as well as the preferable measure of treatment $(1-5,7-20)$. Concerning the former topic, although 22 ascertained cases of HCC deriving from FNH have been described, no clonal analysis of FNH and FNH-related HCC has come to definitive conclusions on malignant potential (7). As for the latter, given the lack of randomized clinical trials, the management algorithm of FNH remains controversial (1). In this regard, we tried to shed more light on treatment options, reviewing their advantages and disadvantages.

\section{Materials and Methods}

We searched the pertinent world literature through 2017 investigating four popular search engines (PubMed, Science Direct, Scopus and Google Scholar). Four main therapy approaches were selected: i) Observational approach (plethora of studies); ii) surgery (profusion of works); iii) radiofrequency ablation (RFA): to date, only one case report has been described; iv) transarterial embolization (TAE), with 17 articles published as of 2017 (Table I) (1, 3-5, 8-20).

\section{Discussion of Treatment Options}

i) Conservative approach. Silent lesions smaller than $4 \mathrm{~cm}$ in diameter can simply be observed and surveilled through imaging studies (1-5, 7-21, 24-27). Such an approach is justified by the minimal risk for bleeding, necrosis and malignant degeneration (12). Furthermore, spontaneous regression, although rare, can always occur, especially following withdrawal of birth control pills in females (1-4). 
ii) Surgery. All lesions becoming symptomatic or developing an increase in tumor size should deserve treatment. Traditionally, open or laparoscopic resection of $\mathrm{FNH}$ (associated or not with hepatic artery ligation) has been advocated as the preferred curative treatment in the case of changes in clinic, radiological or clinicoradiological characteristics (1-5, 7-20). However, there are only limited data evaluating the risk-benefit balance following this type of measure: the morbidity rate has been reported to reach $27 \%$ and $9 \%$ after open and laparoscopic surgery, respectively, with a mortality rate of $2 \%(1,5)$. Some authors warn against such approaches because of these rates after surgery, considering them as serious and unacceptable in the management of a benign disease (12). Related complications include intra- or postoperative bleeding, biliary fistula, ileus, intra-abdominal abscess, liver failure, pleural effusion and deep vein thrombosis (1). Surgery is, however, the recommended procedure in emergency situations characterized by hemoperitoneum due to FNH rupture (21). To date, only one case of recurrent FNH has been described following surgery: a 22-year-old man with a previous history of left-lobe FNH who in fact developed three bilobal lesions 3 years after the first intervention (22). Surgery was the kind of treatment selected also for recurrences. Differently from $\mathrm{HCC}$, no recurrence of FNH has been documented following laparoscopic liver resection thus far (23).

iii) Radiofrequency ablation. In 2010, Hedayati and colleagues described the first (and, to date, the sole) case report of RFA of a $2.2 \mathrm{~cm}$ symptomatic $\mathrm{FNH}$ in a 21 -year-old symptomatic woman. The procedure was safe but only partially effective since a small residual was noted at 2-month follow-up computed tomography (2). Hence, longer-term follow-up is essential to ultimately verify the effectiveness of RFA (2).

iv) Transarterial embolization. We found only 17 articles dealing with TAE applied to FNH (Table I) (1, 3-5, 8-20). Altogether, 128 patients with FNH patients were effectively treated: TAE was performed at least once per patient. Usual indications were unresectable lesions with/without symptoms, patients unfit for surgery, necessity of sparing normal hepatic parenchyma, multiple FNHs, patient refusal to undergo surgery and pediatric patients $(1,3-5,8-20)$. Additionally, TAE has also been used as a form of bridge therapy to surgery in selected cases for size reduction and pain control $(5,16)$. Finally, TAE can also be performed in emergency settings as a ready method of arresting hemorrhage arising from a ruptured FNH (arteriographic hemostatic TAE has been applied to only five cases as of 2017) (22-25). On the other hand, due to the uncertainty about the natural history of FNH and its correlation with HCC, some authors still prefer surgical resection to this minimally invasive approach (15). Besides these oncological considerations, given the vascular nature of this disease, TAE appears a logical strategy of treatment (1, 15). In fact, FNH is usually fed by a single artery which supplies blood from the center to the periphery of the tumor $(1,11,15)$. Commonly, in its course, the feeding artery provides no or little arteriovenous shunting and is unaccompanied by portal vein branches or biliary ducts (50$60 \%$ of cases); this kind of one-vessel FNH is extremely amenable to a single administration of $\operatorname{TAE}(1,3,15)$. In contrast, in the case of multiple small feeding vessels, the necessity for repeat TAE should be anticipated $(1,3,11,15)$. In contrast to surgery, TAE does not require general anesthesia, entails a significantly shorter length of stay (1.4 days versus 9.5 and 1.9 days, respectively, for open, and laparoscopy-assisted surgery) as well as lower morbidity and mortality rates (1). Such a practice is not free from possible complications: main consequences derive from superinfection of embolized tissue and massive discharge of toxic radicals. However, most minor (liver abscess, infection) as well as major adverse events (post-embolization syndrome/tumor lysis syndrome, liver or gallbladder infarction, pneumonia, pleural effusion, renal failure and death) occurred in patients with severe underlying liver diseases, such as portal vein obstruction, cirrhosis, chronic hepatitis and biliary obstruction $(3,12)$. Out of these, inadequacy of the portal blood flow seems to be the most important predisposing risk factor (7). Post-embolization syndrome usually starts within 24-48 hours of embolization and can last up to 7 days (1). It is characterized by pain at the site of treatment, fever or lowgrade temperature, nausea, vomiting, malaise and leukocytosis; its severity depends on the size of the embolized tissue (1). To date, only one case of local recurrence was found in one treated patient at the 54-month follow-up (4).

Currently, what appears still unsolved with TAE is the choice of the best embolization material (1, 3-5, 7-19). In fact, since the first description of TAE in 1979, various agents have been tested and progressively used in the studies in literature: low-diameter polyvinyl alcohol (PVA) particles and ethiodized oil (lipiodol) emulsions have been the most frequently adopted embolic agents (Table I). Hepatic intraarterial administration of PVA causes the permanent occlusion of the terminal hepatic arterioles, whereas the concomitant injection of lipiodol is thought to reduce the blood flow of the terminal portal venules temporarily and embolize the small abnormal vessels within the hyperplastic lesion (3). However, because FNH relies much less on the portal circulation than other tumor types, the use of lipiodol could be a matter of debate. On the other hand, in addition to helping cause ischemia, there is a second effect using this material:direct tumoricidal activity (3). In fact, for reasons that remain unknown, lipiodol adheres to and is phagocytated by hyperplastic Kupffer cells, causing their lysis $(3,11)$. More recently, some authors have introduced the employment of bleomycin in combination with other agents (such as PVA 
Table I. Literature dealing with successful transarterial embolization (TAE) of focal nodular hyperplasia (FNH) of the liver as of 2017.

\begin{tabular}{|c|c|c|c|c|}
\hline Author, year (Ref) & Age, gender, & $\begin{array}{l}\text { Initial FNH size } \\
\text { (no. of patients) }\end{array}$ & $\begin{array}{l}\text { TAE method } \\
(\mathrm{cm})\end{array}$ & Post-TAE complications \\
\hline Pueyo et al., 1979 (8) & $28, \mathrm{~F}$ & $16 \times 10 \times 7$ & $30 \times 2 \mathrm{~mm}$ Gelatin sponge strips & Liver abscess \\
\hline Soucy et al., 1989 (9) & $14, \mathrm{M}$ & $14 \times 9$ & Ethanol & None \\
\hline \multirow[t]{4}{*}{ Pain et al., 1991 (10) } & $3, \mathrm{M}$ & 6 & Embolization plus arterial ligation & None \\
\hline & $30, \mathrm{M}$ & 14 & Embolization plus arterial ligation & None \\
\hline & $33, \mathrm{M}$ & 7 & Embolization & None \\
\hline & $37, \mathrm{~F}$ & 14 & Embolization & None \\
\hline Shuda et al., 2001 (11) & $18, \mathrm{~F}$ & $14 \times 8$ & Lipiodol plus gelfoam particles & None \\
\hline \multirow[t]{2}{*}{ Terkivatan et al., 2002 (12) } & $29, \mathrm{~F}$ & 4 & $150-250 \mu \mathrm{m}$ Contour particles & None \\
\hline & $19, \mathrm{~F}$ & 7 & $150-250 \mu \mathrm{m}$ Contour particles & None \\
\hline Geschwind et al., 2002 (3) & $42, \mathrm{~F}$ & 5 & 150-200 $\mu \mathrm{m}$ PVA plus lipiodol & None \\
\hline Gussick et al., 2005 (13) & $35, \mathrm{~F}$ & $5.5 \times 3.5$ & $150-250 \mu \mathrm{m}$ PVA plus lipiodol & None \\
\hline \multirow[t]{4}{*}{ Vogl et al., 2006 (1) } & $38, \mathrm{~F}$ & $4 \times 4$ & $150-250 \mu \mathrm{m}$ Contour particles & None \\
\hline & $44, \mathrm{~F}$ & $6 \times 5$ & $150-250 \mu \mathrm{m}$ Contour particles & None \\
\hline & $46, \mathrm{~F}$ & $3.2 \times 3.2$ & $150-250 \mu \mathrm{m}$ Contour particles & None \\
\hline & $54, \mathrm{~F}$ & $7 \times 6$ & $150-250 \mu \mathrm{m}$ Contour particles & None \\
\hline \multirow[t]{2}{*}{ Wilhelm et al., 2006 (14) } & $44, \mathrm{~F}$ & $10 \times 8$ & $150-200,500-710 \mu \mathrm{m}$ PVA & None \\
\hline & $35, \mathrm{~F}$ & $14 \times 12$ & $150-200,500-710 \mu \mathrm{m}$ PVA & None \\
\hline \multirow[t]{3}{*}{ Amesur et al., 2009 (15) } & $30, \mathrm{~F}$ & 5 & $300-700 \mu \mathrm{m}$ PVA & None \\
\hline & $32, \mathrm{~F}$ & 9 & $300-700 \mu \mathrm{m}$ PVA & None \\
\hline & $31, \mathrm{~F}$ & 8 and 3 & $300-700 \mu \mathrm{m}$ PVA & Persistent pain \\
\hline Arts et al., 2010 (16) & $36, \mathrm{~F}$ & $6.7 \times 5.2$ & N.A. & None \\
\hline Huang et al., 2011 (17) & (4 Patients, n.o.d.) & N.A. & 500-700 $\mu \mathrm{m}$ PVA plus PLE & None \\
\hline Yan et al., 2012 (18) & (21 Patients, n.o.d.)) & $3.5-9.5$ & PVA plus lipiodol plus bleomycin & None \\
\hline Birn et al., 2013 (5) & 18-61(12 Patients, n.o.d.) & $2.2-14.8$ & $100-300,300-500 \mu \mathrm{m}$ TGM & Persistent pain in two patients \\
\hline \multirow{2}{*}{$\begin{array}{l}\text { Gómez García et al., } \\
2014 \text { (19) }\end{array}$} & $31, \mathrm{~F}$ & $4.8 \times 4.1$ & N.A. & None \\
\hline & $35, \mathrm{~F}$ & $5.8 \times 3.6$ & & \\
\hline Oliveira et al., 2015 (20) & $15, \mathrm{M}$ & 19 & $300-500 \mu \mathrm{m}$ PVA & Transitory PES \\
\hline Zhang et al., 2017 (4) & (23 Patients, n.o.d.) & $5.0 \pm 2.4$ & $\begin{array}{l}300-500 \mu \mathrm{m} \text { PVA plus } \\
\text { lipiodol plus bleomycin }\end{array}$ & One recurrence after 54 months \\
\hline
\end{tabular}

N.A.: Not available; n.o.d.: no other details given; PES: post-embolization syndrome; PLE: pingyangmycin lipiodol emulsion; PVA: polyvinyl alcohol particles; TGM: trisacryl gelatin microspheres.

and iodized oil); this mechanism adds to the sclerosing effect exerted by bleomycin the embolic action of iodinated oil associated with PVA (4). More precisely, bleomycin is thought to affect vascular endothelium inducing a secondary formation of intraluminal microthrombi, thereby resulting in the destruction of the feeding artery of the lesion (4). Sclerosing cholangitis, interstitial pneumonia and pulmonary fibrosis have been described as the major possible complications related to the use of this agent (18). Of note, whatever materials have been employed, the use of microcatheters seems to permit a more precise deposition of the embolization particles in the small feeding arteries (selective and superselective TAE), minimizing the risk of occluding major arterial branches $(12,18)$.

\section{Conclusion}

In conclusion, TAE of FNH can be considered a possible and feasible alternative treatment to surgery in terms of curative effect. Furthermore, its numerous advantages (safety of procedure, low morbidity and mortality, shorter length of hospitalization) make it somewhat preferable in most cases. More studies and randomized clinical trials are needed in order to make the comparison with surgery more scientific and optimize the choice of the most adequate embolic agent to use.

\section{Conflicts of Interest}

The Authors declare no conflicts of interest in regard to this study.

\section{References}

1 Vogl TJ, Own A, Hammerstingl R, Reichel P and Balzer JO: Transarterial embolization as a therapeutic option for focal nodular hyperplasia in four patients. Eur Radiol 16: 670-675, 2006.

2 Hedayati P, van Sonnenberg E, Shamos R, Gillespie T and McMullen W: Treatment of symptomatic focal nodular hyperplasia with percutaneous radiofrequency ablation. J Vasc Interv Radiol 21: 582-585, 2010. 
3 Geschwind JF, Degli MS, Morris JM and Choti MA: Treatment of focal nodular hyperplasia with selective transcatheter arterial embolization using iodized oil and polyvinyl alcohol. Cardiovasc Intervent Radiol 25: 340-341, 2002.

4 Zhang G, Wang M, Duan F, Yuan K, Li K, Yan J and Chang Z: Transarterial embolization with bleomycin for symptomatic hepatic focal nodular hyperplasia. Diagn Interv Radiol 23: 6670, 2017.

5 Birn J, Williams TR, Croteau D, Schwarts S, Sturza S and Getzen T: Transarterial embolization of symptomatic focal nodular hyperplasia. J Vasc Interv Radiol 24: 1647-1655, 2013.

6 Virgilio E, Pucci E, Pilozzi E, Mongelli S, Cavallini M and Ferri M: Reactive nodular fibrous pseudotumor of the gastrointestinal tract and mesentery giving multiple hepatic deposits and associated with colon cancer. Am Surg 78: 262-264, 2012.

7 Koea JB and Yeong ML: Focal nodular hyperplasia and hepatocellular carcinoma: uncommon companions? Pathology 46: 348-350, 2014

8 Pueyo I, Guzmán A, Fernández F, García-Morán M, Medina MF, Faedo I, Rodrigo L and Jiménez JR: Liver abscess complicating embolization of focal nodular hyperplasia. Am J Roentgenol 133: 740-742, 1979.

9 Soucy P, Rasuli P, Chou S and Carpenter B: Definitive treatment of focal nodular hyperplasia of the liver by ethanol embolization. J Pediatr Surg 24: 1095-1097, 1989.

10 Pain JA, Gimson AE, Williams R and Howard ER: Focal nodular hyperplasia of the liver: results of treatment and options in management. Gut 32: 524-527, 1991.

11 Shuda K, Tokunaga A, Sohda T, Watanabe H, Shijo H, Sakisaka S, Kakazu T and Okazaki M: Focal nodular hyperplasia treated by transcatheter arterial embolization using lipiodol mixed with gelfoam particles. J Gastroenterol Hepatol 16: 840-841, 2001

12 Terkivatan T, Hussain SM, Lameris JS and IJzermans JN: Transcatheter arterial embolization as a safe and effective treatment for focal nodular hyperplasia of the liver. Cardiovasc Intervent Radiol 25: 450-453, 2002.

13 Gussick SD, Quebbeman EJ and Rilling WS: Bland embolization of telangiectatic subtype of hepatic focal nodular hyperplasia. J Vasc Interv Radiol 16: 1535-1538, 2005.

14 Wilhelm L, Albrecht L, Kirsch $M$ and Heidecke CD: Preoperative application of selective angiographic embolization in the treatment of focal nodular hyperplasia. Surg Laparosc Percutan Tech 16: 177-181, 2006.

15 Amesur N, Hammond JS, Zajko AB, Geller DA and Gamblin TC: Management of unresectable symptomatic focal nodular hyperplasia with arterial embolization. J Vasc Interv Radiol 20: 543-547, 2009.

16 Arts CH, van Hillegersberg R, de Kort GA and Moll FL: Inferior caval vein thrombosis owing to compression of focal nodular hyperplasia: surgical resection after shrinkage by hepatic artery embolization. Vascular 18: 53-58, 2010.
17 Huang D, Chen Y, Zeng Q, Zhao J, Wu R, Wu X and Li Y: Transarterial embolization using pingyangmycin lipiodol emulsion and polyvinyl alcohol for the treatment of focal nodular hyperplasia of the liver. Hepatogastroenterology 58 : 1736-1741, 2011.

18 Yan JY, Wang MQ, Liu FY, Wang ZJ, Duan F and Song P: Super selective transcatheter arterial embolization for treatment of focal nodular hyperplasia of the liver: report of 21 cases. Zhonghua Yi Xue Za Zhi 92: 2893-2896, 2012.

19 Gómez García MP, Cruz González I, Peña Baranda B, Atín del Campo VM and Méndez Martín JJ: Treatment of symptomatic focal nodular hyperplasia by arterial embolization. Cir Esp 92: 135-137, 2014.

20 Oliveira C, Gil-Agostinho A, Gonçalves I and Noruegas MJ: Transarterial embolisation of a large focal nodular hyperplasia using microspheres in a paediatric patient. BMJ Case Rep 2015: Pii:bcr2014208879, 2015.

21 Demarco MP, Shen P, Bradley RF and Levine EA: Intraperitoneal hemorrhage in a patient with hepatic focal nodular hyperplasia. Am Surg 72: 555-559, 2006.

22 Chung E, Park CH, Kim J, Han NI, Lee YS, Choi HJ, Bae SH and Park IY: Recurrence of multiple focal nodular hyperplasia in a young male patient. Korean J Gastroenterol 64: 49-53, 2014.

23 Virgilio E, Scorsi A, Amodio PM, Goglia A and Macarone Palmieri R: Port site recurrences following laparoscopic liver resection for hepatocellular carcinoma. World J Surg 40: 17781779, 2016.

24 Kinoshita M, Takemura S, Tanaka S, Hamano G, Ito T, Aota T, Koda M, Ohsawa $\mathrm{M}$ and Kubo S. Ruptured focal nodular hyperplasia observed during follow-up: a case report. Surg Case Rep 3: 44, 2017.

25 Chung SW and DeGirolamo KM: Focal Nodular hyperplasia: a case report of rare multiple ruptures of a common liver tumour in a single patient. UBCMJ 3: 40-42, 2011.

26 Cubo Cintas T, Padilla-Valverde D, Villarejo Campos P, López Useros A, Manzanares Campillo C, Martín F and Zarca MA: Management of spontaneous hepatic hemorrhage due to focal nodular hyperplasia. Gastroenterol Hepatol 30: 387-390, 2007.

27 Koch N, Gintzburger D, Seelentag W, Denys A, Gillet M and Halkic N: Rupture of hepatic focal nodular hyperplasia. About two cases. Ann Chir 131: 279-282, 2006.

Received October 14, 2017

Revised October 31, 2017

Accepted November 1, 2017 